\title{
The use of an early postoperative CRH test to assess adrenal function after transsphenoidal surgery for pituitary adenomas
}

\author{
Nieke E. Kokshoorn • Johannes A. Romijn • \\ Ferdinand Roelfsema • Anna H. J. H. Rambach • \\ Johannes W. A. Smit • Nienke R. Biermasz • \\ Alberto M. Pereira
}

Published online: 9 September 2011

(c) The Author(s) 2011. This article is published with open access at Springerlink.com

\begin{abstract}
Transsphenoidal surgery (TS) is the treatment of choice for many pituitary tumors. Because TS may cause pituitary insufficiency in some of these patients, early postoperative assessment of pituitary function is essential for appropriate endocrine management. The aim of our study was to evaluate the clinical relevance of the CRHstimulation test in assessing postoperative pituitary-adrenal function. We performed a retrospective analysis of 144 patients treated by TS between January 1990 and November 2009, in whom a CRH-test and a second stimulation test was performed to assess adrenal function during follow-up. Patients with Cushing's disease were excluded. Hydrocortisone substitution was started if peak cortisol levels were $<550 \mathrm{nmol} / \mathrm{L}$. The cortisol response was insufficient in $42(29 \%)$ and sufficient in 102 patients at the postoperative CRH-test. Thirteen of $42(30 \%)$ demonstrated a normal cortisol response during a second cortisol stimulation test. In 75 of the 102 patients with a sufficient response to $\mathrm{CRH}$ repeat testing revealed an insufficient cortisol response in 14 patients (14\%). All but one had concomitant pituitary hormone deficits. There were no cases of adrenal crises during follow-up. Additional pituitary insufficiency was significantly more present $(P<$ 0.001 ) in the group of patients with an abnormal response to CRH directly after surgery. In this study a substitution strategy of hydrocortisone guided by the postoperative
\end{abstract}

N. E. Kokshoorn $(\bowtie) \cdot$ J. A. Romijn · F. Roelfsema .

A. H. J. H. Rambach · J. W. A. Smit - N. R. Biermasz ·

A. M. Pereira

Department of Endocrinology and Metabolic Diseases C4-R,

Leiden University Medical Center, P.O. Box 9600, 2300 RC

Leiden, The Netherlands

e-mail: n.e.kokshoorn@lumc.nl cortisol response to CRH appeared safe and did not result in any case of adrenal crises. However, the early postoperative $\mathrm{CRH}$-test does not reliably predict adrenal function after TS for pituitary adenomas in all patients and retesting is mandatory.

Keywords CRH · Adrenal insufficiency · Postoperative · Transsphenoidal surgery

\section{Introduction}

Transsphenoidal surgery (TS) is the treatment of choice for many pituitary tumors. TS may result in (additional) pituitary insufficiency in some of these patients [1-3]. Therefore, accurate assessment of pituitary function is essential for appropriate management of postoperative patients after TS. In this respect, evaluation of the pituitary-adrenal axis is clinically relevant to assess the need for hydrocortisone replacement therapy at discharge.

The insulin tolerance test (ITT) is considered to be the gold standard for the evaluation of secondary adrenal insufficiency $[4,5]$. Because there are contraindications for ITT in some patients, the corticotrophin releasing hormone (CRH) test, the metyrapone test or the ACTH stimulation test can be used as alternative dynamic tests to assess adrenal function [6-8]. However, there is no international consensus for postoperative testing after pituitary surgery. We performed a structured literature search for articles that (1) evaluated the postoperative strategy for evaluation of adrenal function and (2) use of the CRH test to evaluate the pituitary-adrenal axis in postoperative patients after TS for pituitary adenomas, excluding manuscripts on patients with Cushing's disease. However, specific data on this topic are hardly available. 
Moreover, studies that compared CRH test and other dynamic test in other situations (i.e. in patients with (suspected) hypothalamic-pituitary insufficiency not specifically related to surgery) reported contradictory results $[8$, 9]. Therefore, at our center we developed a strategy for evaluation of patients after pituitary surgery in 1990 using the CRH test as the first postoperative test. The aim of the present study was to assess the clinical relevance of the CRH stimulation test, as a part of this evaluation strategy, in assessing pituitary-adrenal function after TS. We performed a retrospective analysis of all patients treated by TS between January 1990 and November 2009, in whom a CRH test and a second stimulation test was performed to assess adrenal function during follow-up in non-Cushing patients.

\section{Patients and methods}

\section{Study design}

We performed a retrospective chart review of all patients, who had been treated by TS in the Leiden University Medical Center between January 1990 (when human CRH (hCRH) became available for routine clinical use) and November 2009. Patients with available data on a postsurgical CRH-test, who also had a second (confirmation) test of adrenal function during follow-up were included. We excluded patients on high dose glucocorticoids, reoperation, postoperative cranial radiotherapy, and patients treated by TS for Cushing's disease.

The Medical Ethics Committee of our hospital declared that no formal ethical approval and written informed consent is needed for this anonymous retrospective chart review.

\section{Endocrine assessment}

According to the postoperative protocol, which has been implemented in our hospital, the pituitary-adrenal axis is assessed by CRH test 7-10 days after surgery. The CRH test is performed after an overnight fast, after withdrawal of hydrocortisone for $24 \mathrm{~h}$, using $100 \mu \mathrm{g}$ CRH (Corticoliberine, Ferring Farmaceuticals Hoofddorp, the Netherlands). Venous blood samples for measurement of ACTH and cortisol concentrations are collected at $-15,0,15,30,45$ and 60 min after infusion. A peak plasma cortisol of $\geq 550 \mathrm{nmol} / \mathrm{L}$ is considered to reflect a normal response $[10,11]$.

In case of insufficient cortisol responses to $\mathrm{CRH}$, hydrocortisone is prescribed $(20 \mathrm{mg} /$ day, divided in three doses). During follow-up, the treating endocrinologist decided on re-testing of the adrenal function. For the assessment of the HPA axis during follow-up either basal serum cortisol levels or a stimulation test was used. The
ITT was performed after an overnight fast by intravenous administration of insulin $(0.10 \mathrm{U} / \mathrm{kg}$, Actrapid, Novo Nordisk Farma, Bagsvaerd, Denmark) to induce adequate hypoglycemia, defined as nadir glucose levels $<2.2 \mathrm{mmol} / \mathrm{L}$. Blood was collected for measurement of cortisol, ACTH and GH at $-15,0,15,30,45,60,90$ and 120 min after iv administration of insulin. Peak values of $\mathrm{GH}>9 \mathrm{mU} / \mathrm{L}$ (corresponding with $3 \mu \mathrm{g} / \mathrm{L}$ ) and cortisol of $\geq 550 \mathrm{nmol} / \mathrm{L}$ were considered to reflect normal pituitary function of $\mathrm{GH}$ and ACTH secretion [4, 12-15].

For the ACTH test $1 \mu \mathrm{g}$ Synacthen (Novartis Pharma, Arnhem, The Netherlands) was administered i.v. and cortisol levels were measured at $-15,0$ and $30 \mathrm{~min}$ after infusion. A peak cortisol value of $\geq 550 \mathrm{nmol} / \mathrm{L}$ was considered to reflect normal adrenal reserve [16-18]. In addition, a basal serum cortisol concentration of $>550 \mathrm{nmol} / \mathrm{L}$ was considered to reflect normal adrenal function [9].

In some patients a metyrapone test was used as a second test to assess pituitary adrenal function. Metyrapone (30 mg/kg, Metopiron, Novartis Pharma B.V., Arnhem, the Netherlands) was administered orally at midnight. The next morning postabsorptive blood samples were obtained for measurement of 11-deoxycortisol, cortisol and ACTH levels. A cut-off value for 11-deoxycortisol of $200 \mathrm{nmol} / \mathrm{L}$ was used to define normal adrenal function $[6,19,20]$.

\section{Assays}

Between 1986 and 1994, a fluorescence energy-transfer immunoassay Syva-Advance (Syva Company, Palo Alto, CA) was used, with an interassay variation coefficient of $3.6-6.1 \%$ and a detection limit of $50 \mathrm{nmol} / \mathrm{L}$. From 1994, cortisol was measured by fluorescencepolarization assay on a TDx (Abbott Laboratories, Abbott Park, IL). The interassay variation coefficient is $5-6 \%$ above $500 \mathrm{nmol} / \mathrm{L}$ and amounts to $12 \%$ under $200 \mathrm{nmol} / \mathrm{L}$. The detection limit is $20 \mathrm{nmol} / \mathrm{L}$. The methods correlated well with each other, and therefore no correction factors were introduced for follow-up of patients. ACTH was determined by immunolimunimetric assay using an Immulite 2500 (Siemens Healthcare Diagnostics, Deerfield, IL, USA). The maximal inter-assay coefficient of variation (CV) was between 5.0 and $10.0 \%$. During the insulin tolerance test glucose levels were measured using a Modular P800 (Roche Diagnostics, Mannheim, Germany).

For the measurement of 11-deoxycortisol a radioimmunoassay (RIA) of Diasource (previously Biosource Europe, Nivelles, Belgium) was used. CV was approximately $11 \%$.

FT4, TSH, LH, FSH and prolactine blood levels were measured by electrochemoluminescent immunoassay (ECLIA), using a Modular E170, (Roche Diagnostics, Mannheim, Germany). The maximal inter-assay CV for 
these hormones was 5.0\%. ACTH, GH and IGF-I were determined by immunolimunimetric assay using an Immulite 2500 (Siemens Healthcare Diagnostics, Deerfield, IL, USA). The maximal inter-assay CV was between 5.0 and $10.0 \%$. Glucose levels were measured using a Modular P800 (Roche Diagnostics Mannheim, Germany) (CV is $3 \%$ ). For measurement of estradiol levels a RIA (Orion Diagnostica, Espoo, Finland) was used (CV is $6 \%$ at $70 \mathrm{pmol} / \mathrm{L}$ ). The estradiol detection limit was $20 \mathrm{pmol} / \mathrm{L}$. Testosterone was measured using a RIA (Siemens Healthcare Diagnostics, Deerfield IL, USA). (CV is $20 \%$ at $1.0 \mathrm{nmol} / \mathrm{L}$ and $12 \%$ at $14 \mathrm{nmol} / \mathrm{L}$ ) The detection limit was $0.2 \mathrm{nmol} / \mathrm{L}$.

\section{Statistical analysis}

PSAW for Windows version 17.0 (SPSS Inc. Chicago, IL) was used to perform data analysis. Data are presented as mean \pm SD unless otherwise mentioned. To evaluate the difference between peak cortisol of the direct postsurgical $\mathrm{CRH}$ test and the confirmation test during follow-up we used a paired t-test. A $\chi^{2}$-test was used to evaluate the difference in prevalence of additional pituitary insufficiency in patients diagnosed with or without adrenal insufficiency based on the CRH stimulation test. The level of significance was set at $P \leq 0.05$.

\section{Results}

Patients

Between January 1990 and November 2009, 291 patients were treated by TS for non-functioning pituitary adenomas (NFA, $\mathrm{n}=160)$, GH-producing adenomas $(\mathrm{n}=96)$, prolactinomas $(\mathrm{n}=16)$ or other pituitary tumors $(\mathrm{n}=19)$ (Fig. 1). A CRH test directly following surgery was not indicated in 13 patients because of cortisol levels below or above the reference rages of normal $(<100 \mathrm{nmol} / \mathrm{L}$ and $>550 \mathrm{nmol} / \mathrm{L}$, respectively). In addition no CRH test was performed in 69 patients for several reasons: pituitary insufficiency prior to surgery $n=29$, follow-up in outpatient clinic $n=11$, peri-operative steroid use $n=5$, ITT directly after surgery $n=7$ and loss to follow-up $n=30$. Consequently, a CRH test was performed in 209 postoperative patients after TS. In 65 of these 209 patients, there was no additional adrenal test performed in follow-up between TS and referral for postoperative radiotherapy $(\mathrm{n}=24)$, repeat surgery $(\mathrm{n}=5)$, or death of the patient $(\mathrm{n}=10)$, or due to follow-up in another hospital $(\mathrm{n}=17)$ and loss to follow-up $(\mathrm{n}=9)$ ). Therefore, 144 patients were finally included in this study. Baseline characteristics of these 144 patients are presented in Table 1.

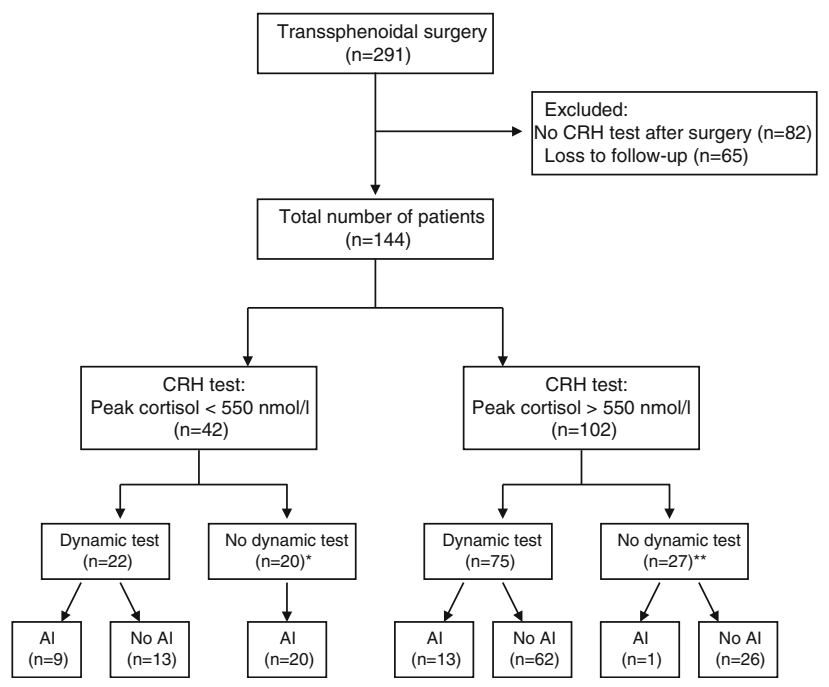

Fig. 1 Flow-chart of patient selection and follow-up. $A I=$ adrenal insufficiency. *pre-existent panhypopituitarism before or immediately after surgery $(\mathrm{n}=12)$, pre-existent isolated severe adrenal insufficiency before surgery $(n=4)$ or very low basal serum cortisol concentrations (mean $10 \mathrm{nmol} / \mathrm{L}$ ) during follow-up after surgery $(\mathrm{n}=4)$. **basal serum cortisol levels $>550 \mathrm{nmol} / \mathrm{L}(\mathrm{n}=12)$, normal urine cortisol levels $(n=3)$, short follow-up between repeated surgery or additional radiotherapy $(\mathrm{n}=2)$, and follow-up $<1$ year $(\mathrm{n}=2)$ or unspecified reasons $(n=7)$, basal serum cortisol $<110 \mathrm{nmol} / \mathrm{L}(\mathrm{n}=1)$

Table 1 Baseline characteristics

\begin{tabular}{ll}
\hline Baseline characteristics & $\begin{array}{l}\text { Number of patients } \\
(\mathrm{n}=144)\end{array}$ \\
\hline Gender (M/F) & $71 / 73$ \\
Age (years) & $50(15-83)$ \\
Diagnosis (n) & \\
NFA & 70 \\
Acromegaly & 63 \\
Prolactinoma & 6 \\
Other pituitary tumors & 5 \\
Time between CRH test and confirmation test & $25.5\left(2\right.$ days $^{\mathrm{a}}-$ \\
(months) & 219 months $)$ \\
Confirmation test (n =97) & \\
ITT & 55 \\
CRH & 16 \\
ACTH stimulation test & 21 \\
Metyrapone test & 5
\end{tabular}

${ }^{a}$ Basal serum cortisol was low, however CRH test peak cortisol 0.61 therefore 2 days after CRH test a metyrapone test was performed

Patients with a decreased postoperative cortisol response to $\mathrm{CRH}(\mathrm{n}=42)$

The peak levels of cortisol during the postoperative CRHtest classified 42 of the 144 patients with pituitary-adrenal insufficiency (peak cortisol $<550 \mathrm{nmol} / \mathrm{L}$ ) (Fig. 1). In 22 of these 42 patients with a median peak cortisol response to 
CRH of 480(30-547) nmol/L, a second stimulation test was performed during follow-up: ITT $(\mathrm{n}=8)$, ACTH stimulation test $(n=8), \mathrm{CRH}$ stimulation test $(\mathrm{n}=5)$ and metyrapone test $(n=1)$. These confirmation tests were performed with a median interval of 27.5 (1-139) months after the initial postoperative $\mathrm{CRH}$ test. Based on this repeat test, 9 of these $22(41 \%)$ patients had persistent adrenal insufficiency [median initial cortisol response 356 (30-547); median cortisol response confirmation test 219 (3-514)], who received hydrocortisone replacement and 13 $(59 \%)$ with a normal response, in whom HC was discontinued. In these 13 patients, the median peak cortisol level to postoperative CRH stimulation was 480 (340-543) $\mathrm{nmol} / \mathrm{L}$, whereas the median peak cortisol level during the second test were $672(570-890) \mathrm{nmol} / \mathrm{L}(P<0.001)$. The clinical characteristics of these patients are detailed in Table 2. Based on the results of the $\mathrm{CRH}$ test 4 patients did not receive $\mathrm{HC}$ directly after surgery, or only if necessary. In two of these patients (Table 3 patient 2 and 8) the physician defined the HPA axis as normal based on the peak cortisol of the CRH test (540 and $543 \mathrm{nmol} / \mathrm{L}$ respectively). No clinical events were reported.

In 20 of these 42 patients with a median $\mathrm{CRH}$ stimulated cortisol concentration of 194 (6-510) nmol/L, no additional stimulation test of adrenal function was performed during follow-up. Persistent adrenal insufficiency was considered to be present in these 20 patients because of pre-existent panhypopituitarism before or immediately after surgery $(n=12)$, pre-existent isolated severe adrenal insufficiency before surgery $(n=4)$ or very low basal serum cortisol concentrations (mean $10 \mathrm{nmol} / \mathrm{L}$ ) during follow-up after surgery $(n=4)$. Accordingly, all these patients received hydrocortisone supplementation directly after the post surgical CRH test until now.

\section{Patients with a normal postoperative cortisol response} to $\mathrm{CRH}(\mathrm{n}=102)$

The peak levels of cortisol during the postoperative CRHtest classified 102 of the 144 patients with normal pituitaryadrenal function (peak cortisol $>550 \mathrm{nmol} / \mathrm{L}$ ) (Fig. 1). In 75 of these 102 patients, adrenal function was assessed during follow-up using a second stimulation test in the remaining 27 no stimulation test was used because of basal serum cortisol levels $>550 \mathrm{nmol} / \mathrm{L}(\mathrm{n}=12)$, normal urine cortisol levels $(n=3)$, short follow-up between repeated surgery or additional radiotherapy $(\mathrm{n}=2)$, and follow-up $<1$ year $(n=2)$ or unspecified reasons $(n=7)$. One patient returned within 3 months after surgery with complaints and basal postabsorptive serum cortisol levels of $90 \mathrm{nmol} / \mathrm{L}$ and HC was started without additional stimulation test. The ITT was used in 49 of the 75 patients, the $\mathrm{CRH}$ test in 11 patients, the ACTH stimulation test in 11, and the metyrapone test in four patients. A normal response to these tests was found in 62 patients. However, 13 patients had an insufficient adrenal response to these tests. With the inclusion of the patient with very low basal serum cortisol levels (see above), 14 patients were classified as adrenal insufficient (Table 3). Thirteen of these 14 patients had been diagnosed with any other additional pituitary insufficiencies and eight of these patients (57\%) had panhypopituitarism. Six patients already received HC directly after surgery. None of these 14 patients experienced any clinical event related to cortisol deficiency.

\section{Prevalence of additional pituitary insufficiency}

A total of 73 patients had additional pituitary insufficiency. The prevalence of additional pituitary insufficiency was significantly higher in patients diagnosed with an insufficient $\mathrm{CRH}$ stimulation test after surgery compared to patients with a normal test result (any hypopituitarism $P<0.001$; GHD $P<0.001$; TSH deficiency $P<0.001$; LH/FSH deficiency $P=0.001)$.

\section{Discussion}

This study evaluated the postoperative response of cortisol to CRH stimulation in a large cohort of patients after TS for pituitary adenomas compared with the adrenal function assessed during postoperative follow-up. The second adrenal function test documented a normal cortisol response in $31 \%$ of the patients with a decreased cortisol response to CRH stimulation directly after surgery. Conversely, the second adrenal stimulation test documented an insufficient cortisol response in $14 \%$ of the patients with a normal cortisol response to direct postoperative $\mathrm{CRH}$ stimulation. Therefore, the postoperative $\mathrm{CRH}$ test does not reliably predict adrenal function after TS for pituitary adenomas in all patients. Nonetheless, our substitution strategy of hydrocortisone guided by the postoperative cortisol responses to $\mathrm{CRH}$ did not result in any case of adrenal crises in our patients.

Although $\mathrm{CRH}$ stimulation has been incorporated in the diagnostic procedures of ACTH dependent Cushing's syndrome [21-23], reports on the use of CRH stimulation to assess cortisol dependency after transsphenoidal surgery for other pituitary adenomas are scarce. We found three publications that assessed pituitary function using $\mathrm{CRH}$, but these were not specifically in patients after transsphenoidal surgery [8, 9]. Dullaart et al. [9] and Schmidt et al. [8] compared the CRH test with basal serum cortisol levels and found no higher diagnostic applicability of the $\mathrm{CRH}$ test to basal morning cortisol levels. In contrast, Maghnie et al. concluded that the $\mathrm{CRH}$ test provided better results than the short Synacthen test (SST) and low-dose short 


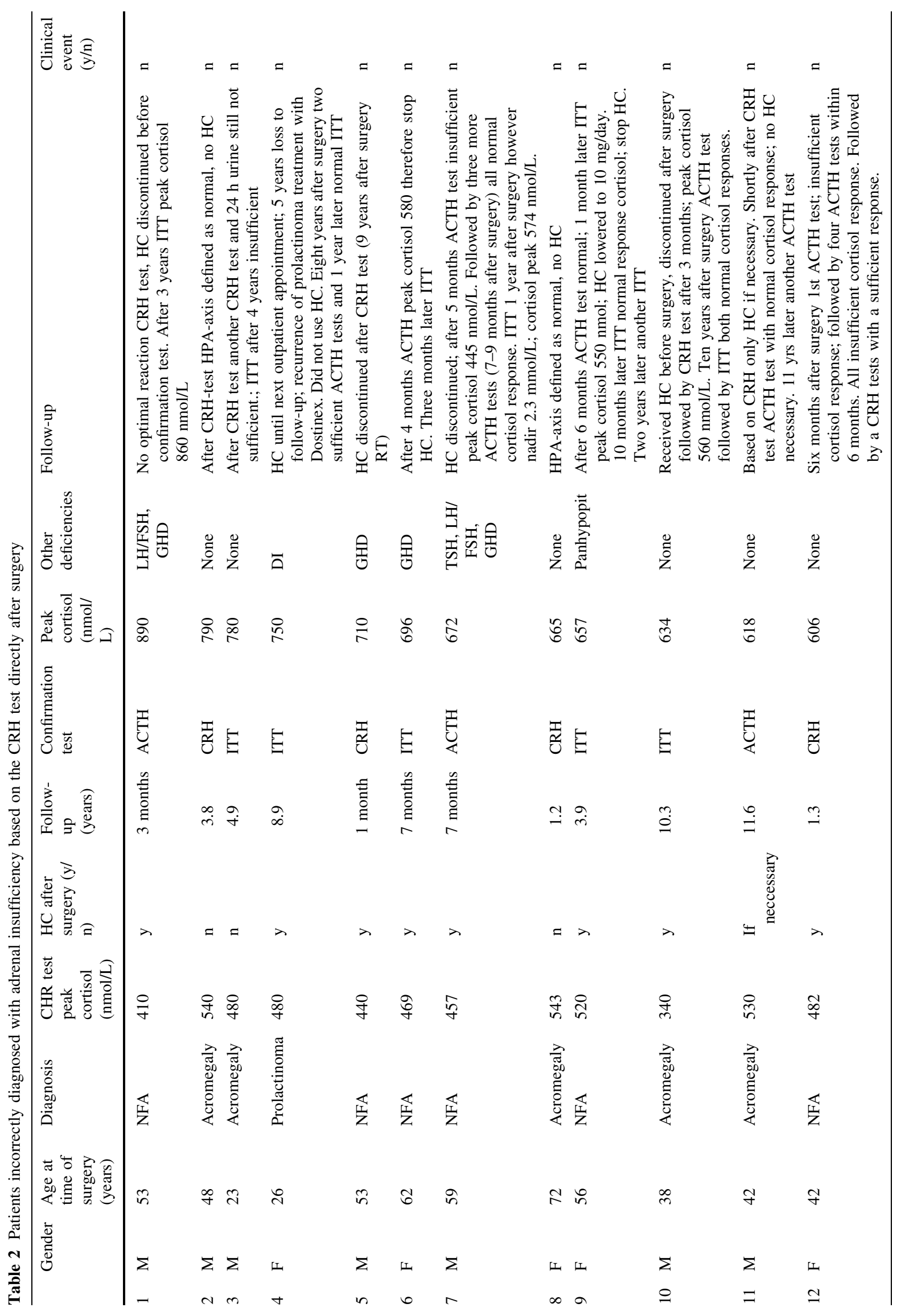


Synacthen test (LDSST), and that CRH may be useful in patients who have a contraindication for ITT [7].

In the current study, the postoperative $\mathrm{CRH}$ stimulation test classified 42 of the 144 patients with hypocortisolism. However, 13 of these patients had sufficient adrenal function during follow-up. There are several explanations for these discrepant results. They may be related to differences in cutoff values of the different tests. Regularly accepted cut-off values $(500-550 \mathrm{nmol} / \mathrm{L})$ have been defined for the ITT, which still remains the gold standard test for the assessment of the HPA-axis. For the CRH test, some authors have proposed different cut-off values for peak cortisol responses. For example, Schmidt et al. [8] reported an optimal peak cortisol cut off of $<377 \mathrm{nmol} / \mathrm{L}$, yielding a $96 \%$ specificity, but poor sensitivity of $76 \%$ for the diagnosis of adrenal insufficiency. A sensitivity of $100 \%$ was reached using a peak cortisol levels of $514 \mathrm{nmol} / \mathrm{L}$ (with a specificity of $32 \%$ ), and $100 \%$ specificity with peak cortisol levels of $349 \mathrm{nmol} / \mathrm{L}$ (sensitivity 66\%). Dullaart et al. found that a peak cortisol value of $420 \mathrm{nmol} / \mathrm{L}$ reflected $100 \%$ specificity, but $100 \%$ sensitivity for the CRH test was only reached using a peak cortisol of $615 \mathrm{nmol} / \mathrm{L}$. Because in our center the CRH test is used as a screening test for hypocortisolism after TS to identify those patients that require hydrocortisone supplementation, we applied a generally accepted stringent criterion of $550 \mathrm{nmol} / \mathrm{L}$. The data indicate that this choice for a higher sensitivity of the $\mathrm{CRH}$ test is at the expense of a lower specificity. In other words, using this strategy a higher proportion of patients will be incorrectly diagnosed with adrenal insufficiency. Based on the available literature the use of a cut-off levels of peak cortisol of $514 \mathrm{nmol} / \mathrm{L}$ would have resulted in $4 / 13$ patients which would not have been diagnosed with adrenal insufficiency, but with the criteria suggested by Dullaart et al. even more patients would have had discrepant results $[8,9]$.

Recovery of preoperative adrenal insufficiency following TS has been described previously [24, 25]. In a recent study that compared the ITT response at 3 and 12 months after TS, recovery of adrenal function was demonstrated within the first year [26]. In agreement, we found a normal function of the HPA-axis in eight patients within the first year after surgery who were initially diagnosed as being adrenal insufficient, indicating the necessity of an extensive follow-up in patients after surgery within one year.

In the current study, the postoperative $\mathrm{CRH}$ test classified 102 of the 144 patients as having a normal functioning of the HPA-axis based on the post-operative CRH test. Fourteen percent of these patients later proved to have hypocortisolism by a second test. These discrepant test results can be potentially life-threatening because these patients are at risk for adrenal crises. It is possible that additional pituitary insufficiencies affected pituitary-adrenal function. Growth hormone and thyroid hormone deficiency can influence these test results. Growth hormone replacement therapy in patients 


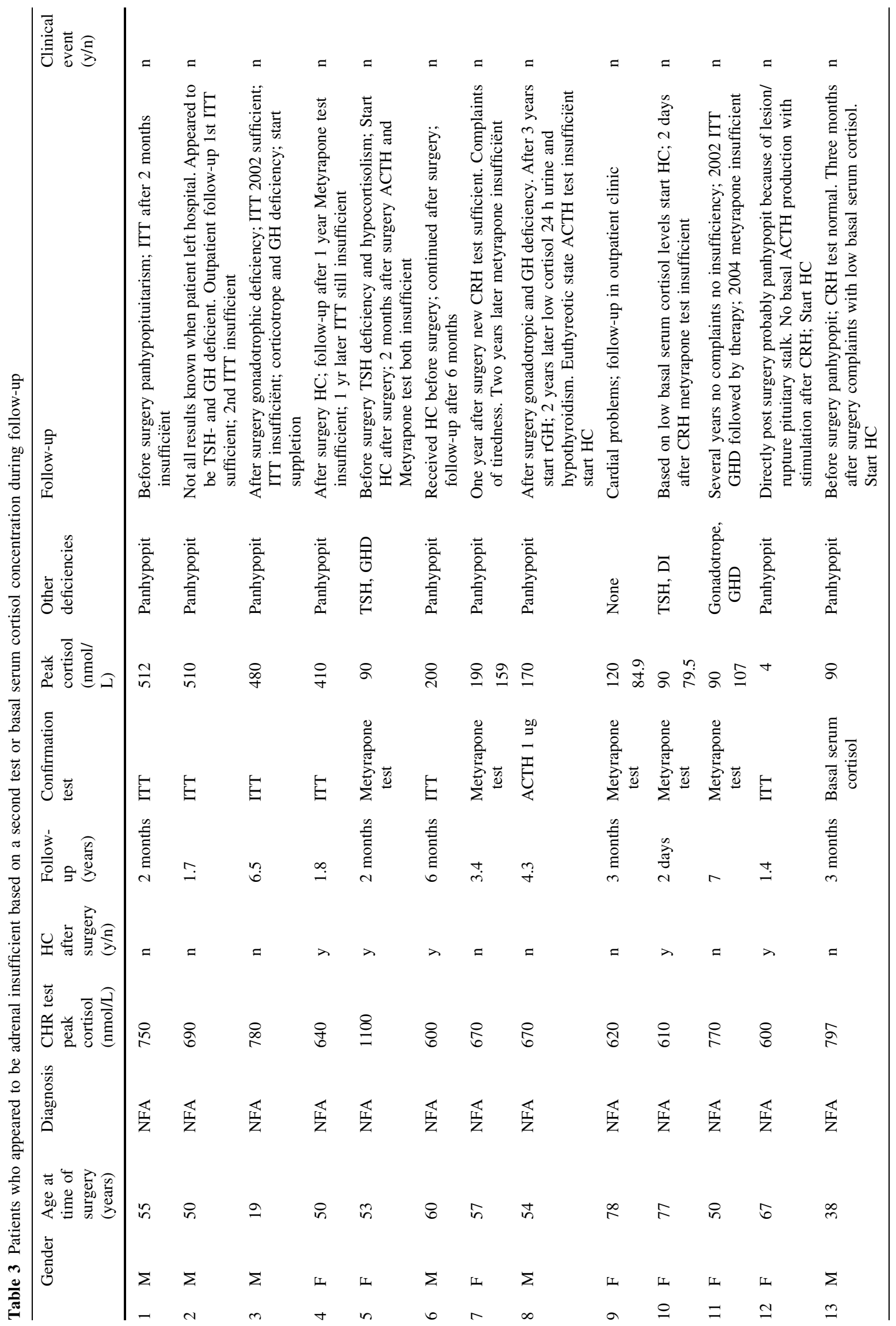



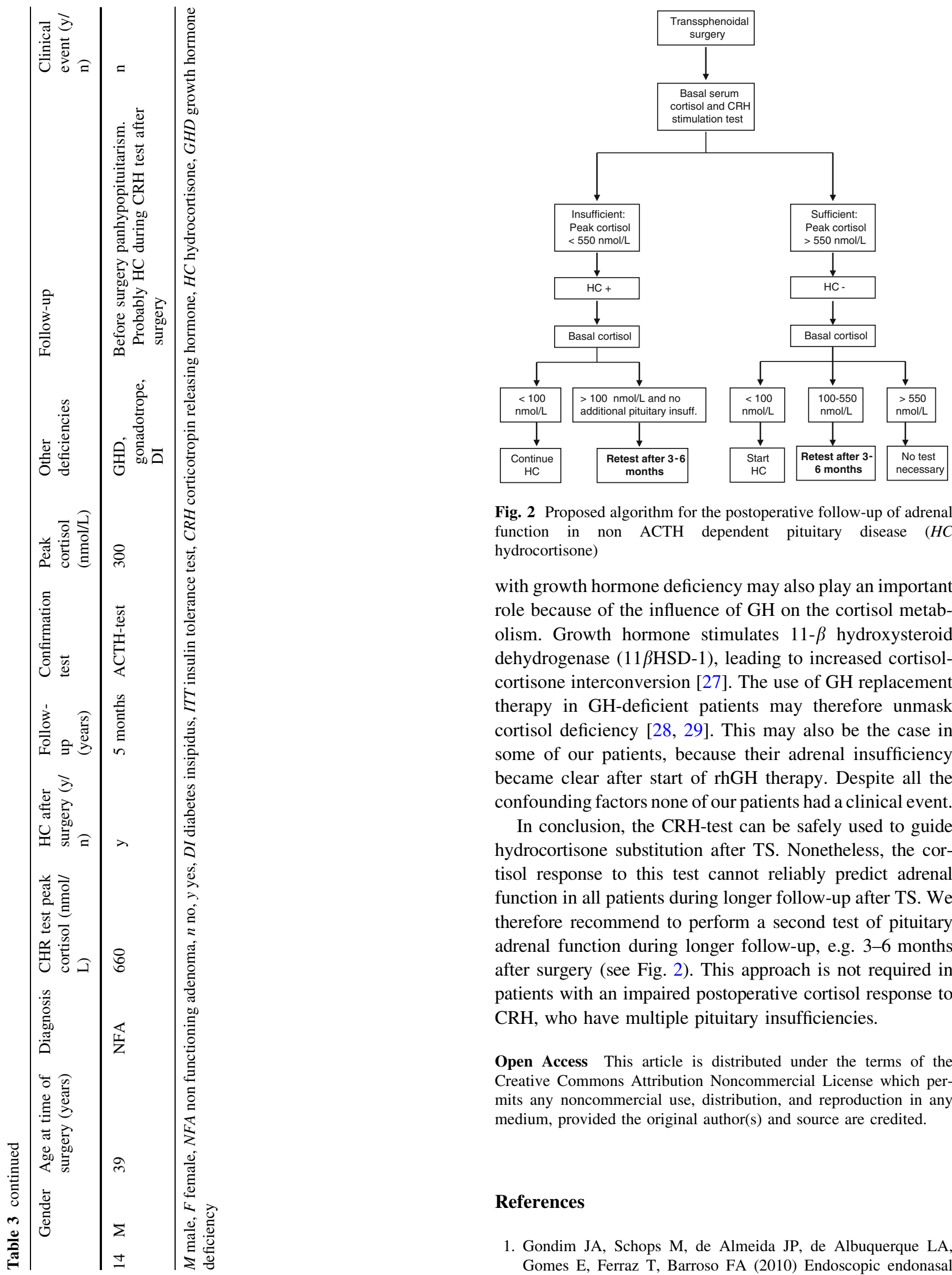

Fig. 2 Proposed algorithm for the postoperative follow-up of adrenal function in non ACTH dependent pituitary disease (HC hydrocortisone)

with growth hormone deficiency may also play an important role because of the influence of $\mathrm{GH}$ on the cortisol metabolism. Growth hormone stimulates 11- $\beta$ hydroxysteroid dehydrogenase (11 $\beta$ HSD-1), leading to increased cortisolcortisone interconversion [27]. The use of GH replacement therapy in GH-deficient patients may therefore unmask cortisol deficiency [28, 29]. This may also be the case in some of our patients, because their adrenal insufficiency became clear after start of rhGH therapy. Despite all the confounding factors none of our patients had a clinical event.

In conclusion, the CRH-test can be safely used to guide hydrocortisone substitution after TS. Nonetheless, the cortisol response to this test cannot reliably predict adrenal function in all patients during longer follow-up after TS. We therefore recommend to perform a second test of pituitary adrenal function during longer follow-up, e.g. 3-6 months after surgery (see Fig. 2). This approach is not required in patients with an impaired postoperative cortisol response to $\mathrm{CRH}$, who have multiple pituitary insufficiencies.

Open Access This article is distributed under the terms of the Creative Commons Attribution Noncommercial License which permits any noncommercial use, distribution, and reproduction in any medium, provided the original author(s) and source are credited.

\section{References}

1. Gondim JA, Schops M, de Almeida JP, de Albuquerque LA, Gomes E, Ferraz T, Barroso FA (2010) Endoscopic endonasal 
transsphenoidal surgery: surgical results of 228 pituitary adenomas treated in a pituitary center. Pituitary 13:68-77

2. Tabaee A, Anand VK, Barron Y, Hiltzik DH, Brown SM, Kacker A, Mazumdar M, Schwartz TH (2009) Endoscopic pituitary surgery: a systematic review and meta-analysis. J Neurosurg 111:545-554

3. Gondim JA, Almeida JP, Albuquerque LA, Schops M, Gomes E, Ferraz T, Sobreira W, Kretzmann MT (2011) Endoscopic endonasal approach for pituitary adenoma: surgical complications in 301 patients. Pituitary 14:174-183

4. Fish HR, Chernow B, O’Brian JT (1986) Endocrine and neurophysiologic responses of the pituitary to insulin-induced hypoglycemia: a review. Metabolism 35:763-780

5. Grinspoon SK, Biller BM (1994) Clinical review 62: laboratory assessment of adrenal insufficiency. J Clin Endocrinol Metab 79:923-931

6. Courtney $\mathrm{CH}$, McAllister AS, McCance, Hadden, Leslie H, Sheridan B, Atkinson AB (2000) The insulin hypoglycaemia and overnight metyrapone tests in the assessment of the hypothalamic-pituitary-adrenal axis following pituitary surgery. Clin Endocrinol (Oxf) 53:309-312

7. Maghnie M, Uga E, Temporini F, Di IN, Secco A, Tinelli C, Papalia A, Casini MR, Loche S (2005) Evaluation of adrenal function in patients with growth hormone deficiency and hypothalamic-pituitary disorders: comparison between insulin-induced hypoglycemia, low-dose ACTH standard ACTH and CRH stimulation tests. Eur J Endocrinol 152:735-741

8. Schmidt IL, Lahner H, Mann K, Petersenn S (2003) Diagnosis of adrenal insufficiency: evaluation of the corticotropin-releasing hormone test and Basal serum cortisol in comparison to the insulin tolerance test in patients with hypothalamic-pituitaryadrenal disease. J Clin Endocrinol Metab 88:4193-4198

9. Dullaart RP, Pasterkamp SH, Beentjes JA, Sluiter WJ (1999) Evaluation of adrenal function in patients with hypothalamic and pituitary disorders: comparison of serum cortisol, urinary free cortisol and the human-corticotrophin releasing hormone test with the insulin tolerance test. Clin Endocrinol (Oxf) 50:465-471

10. Lytras N, Grossman A, Perry L, Tomlin S, Wass JA, Coy DH, Schally AV, Rees LH, Besser GM (1984) Corticotrophin releasing factor: responses in normal subjects and patients with disorders of the hypothalamus and pituitary. Clin Endocrinol (Oxf) 20:71-84

11. Trainer PJ, Faria M, Newell-Price J, Browne P, Kopelman P, Coy DH, Besser GM, Grossman AB (1995) A comparison of the effects of human and ovine corticotropin-releasing hormone on the pituitary-adrenal axis. J Clin Endocrinol Metab 80:412-417

12. Arlt W (2008) Adrenal insufficiency. Clin Med 8:211-215

13. Dorin RI, Qualls CR, Crapo LM (2003) Diagnosis of adrenal insufficiency. Ann Intern Med 139:194-204

14. Erturk E, Jaffe CA, Barkan AL (1998) Evaluation of the integrity of the hypothalamic-pituitary-adrenal axis by insulin hypoglycemia test. J Clin Endocrinol Metab 83:2350-2354

15. Jacobs HS, Nabarro JD (1969) Tests of hypothalamic-pituitaryadrenal function in man. Q J Med 38:475-491

16. Abdu TA, Elhadd TA, Neary R, Clayton RN (1999) Comparison of the low dose short synacthen test (1 microg), the conventional dose short synacthen test (250 microg), and the insulin tolerance test for assessment of the hypothalamo-pituitary-adrenal axis in patients with pituitary disease. J Clin Endocrinol Metab $84: 838-843$

17. Mayenknecht J, Diederich S, Bahr V, Plockinger U, Oelkers W (1998) Comparison of low and high dose corticotropin stimulation tests in patients with pituitary disease. J Clin Endocrinol Metab 83:1558-1562

18. Nye EJ, Grice JE, Hockings GI, Strakosch CR, Crosbie GV, Walters MM, Jackson RV (1999) Comparison of adrenocorticotropin $(\mathrm{ACTH})$ stimulation tests and insulin hypoglycemia in normal humans: low dose, standard high dose, and 8-hour ACTH(1-24) infusion tests. J Clin Endocrinol Metab 84:3648-3655

19. Fiad TM, Kirby JM, Cunningham SK, McKenna TJ (1994) The overnight single-dose metyrapone test is a simple and reliable index of the hypothalamic-pituitary-adrenal axis. Clin Endocrinol (Oxf) 40:603-609

20. Staub JJ, Noelpp B, Girard J, Baumann JB, Graf S, Ratcliffe JG (1979) The short metyrapone test: comparison of the plasma ACTH response to metyrapone and insulin-induced hypoglycaemia. Clin Endocrinol (Oxf) 10:595-601

21. Arnaldi G, Angeli A, Atkinson AB, Bertagna X, Cavagnini F, Chrousos GP, Fava GA, Findling JW, Gaillard RC, Grossman AB, Kola B, Lacroix A, Mancini T, Mantero F, Newell-Price J, Nieman LK, Sonino N, Vance ML, Giustina A, Boscaro M (2003) Diagnosis and complications of Cushing's syndrome: a consensus statement. J Clin Endocrinol Metab 88:5593-5602

22. Lindsay JR, Nieman LK (2005) Differential diagnosis and imaging in Cushing's syndrome. Endocrinol Metab Clin North Am 34:403-421

23. Newell-Price J, Bertagna X, Grossman AB, Nieman LK (2006) Cushing's syndrome. Lancet 367:1605-1617

24. Arafah BM (1986) Reversible hypopituitarism in patients with large nonfunctioning pituitary adenomas. J Clin Endocrinol Metab 62:1173-1179

25. Webb SM, Rigla M, Wagner A, Oliver B, Bartumeus F (1999) Recovery of hypopituitarism after neurosurgical treatment of pituitary adenomas. J Clin Endocrinol Metab 84:3696-3700

26. Berg C, Meinel T, Lahner H, Mann K, Petersenn S (2010) Recovery of pituitary function in the late-postoperative phase after pituitary surgery: results of dynamic testing in patients with pituitary disease by insulin tolerance test 3 and 12 months after surgery. Eur J Endocrinol 162:853-859

27. Moore JS, Monson JP, Kaltsas G, Putignano P, Wood PJ, Sheppard MC, Besser GM, Taylor NF, Stewart PM (1999) Modulation of 11 beta-hydroxysteroid dehydrogenase isozymes by growth hormone and insulin-like growth factor: in vivo and in vitro studies. J Clin Endocrinol Metab 84:4172-4177

28. Giavoli C, Libe R, Corbetta S, Ferrante E, Lania A, Arosio M, Spada A, Beck-Peccoz P (2004) Effect of recombinant human growth hormone $(\mathrm{GH})$ replacement on the hypothalamic-pituitary-adrenal axis in adult GH-deficient patients. J Clin Endocrinol Metab 89:5397-5401

29. Rodriguez-Arnao J, Perry L, Besser GM, Ross RJ (1996) Growth hormone treatment in hypopituitary GH deficient adults reduces circulating cortisol levels during hydrocortisone replacement therapy. Clin Endocrinol (Oxf) 45:33-37 